\title{
Bottom slamming on heaving point absorber wave energy devices
}

\author{
Griet De Backer $\cdot$ Marc Vantorre $\cdot$ Peter Frigaard • \\ Charlotte Beels $\cdot$ Julien De Rouck
}

Received: 25 May 2009/Accepted: 28 December 2009/Published online: 25 February 2010

(C) JASNAOE 2010

\begin{abstract}
Oscillating point absorber buoys may rise out of the water and be subjected to bottom slamming upon reentering the water. Numerical simulations are performed to estimate the power absorption, the impact velocities and the corresponding slamming forces for various slamming constraints. Three buoy shapes are considered: a hemisphere and two conical shapes with deadrise angles of $30^{\circ}$ and $45^{\circ}$, with a waterline diameter of $5 \mathrm{~m}$. The simulations indicate that the risk of rising out of the water is largely dependent on the buoy draft and sea state. Although associated with power losses, emergence occurrence probabilities can be significantly reduced by adapting the control parameters. The magnitude of the slamming load is severely influenced by the buoy shape. The ratio between the peak impact load on the hemisphere and that on the $45^{\circ}$ cone is approximately 2 , whereas the power absorption is only $4-8 \%$ higher for the $45^{\circ}$ cone. This work illustrates the need to include slamming considerations aside from power absorption criteria in the buoy shape design process and the control strategy.
\end{abstract}

Keywords Emergence occurrence probability . Impact · Point absorber · Slamming · Wave energy

G. De Backer · M. Vantorre $(\square)$ - C. Beels · J. De Rouck Department of Civil Engineering, Ghent University, Technologiepark Zwijnaarde 904, 9050 Zwijnaarde, Belgium e-mail: marc.vantorre@ugent.be

G. De Backer

e-mail: griet.debacker@ugent.be

P. Frigaard

Department of Civil Engineering, Aalborg University,

Sohngaardsholmsvej 57, 9000 Aalborg, Denmark

e-mail: pf@civil.aau.dk

\section{List of symbols}

$b \quad$ Wet radius at the instantaneous free water surface (m)

$b_{\text {hyd }} \quad$ Hydrodynamic damping coefficient $(\mathrm{kg} / \mathrm{s})$

$b_{\text {ext }} \quad$ External damping coefficient $(\mathrm{kg} / \mathrm{s})$

$C_{\mathrm{s}} \quad$ Slamming force coefficient (-)

$C_{\mathrm{w}} \quad$ Wetting factor (-)

$d \quad$ Draft (m)

$f \quad$ Frequency $(\mathrm{Hz})$

$f_{i} \quad$ Frequency component $(\mathrm{Hz})$

$f_{\mathrm{p}} \quad$ Peak frequency $(\mathrm{Hz})$

$F \quad$ Force $(\mathrm{N})$

$F_{\text {ex }} \quad$ Exciting force $(\mathrm{N})$

$g \quad$ Gravitational acceleration $\left(\mathrm{m} / \mathrm{s}^{2}\right)$

$h \quad$ Drop height (m)

$H_{\mathrm{s}} \quad$ Significant wave height $(\mathrm{m})$

$k \quad$ Hydrostatic restoring coefficient $\left(\mathrm{kg} / \mathrm{s}^{2}\right)$

$K_{\mathrm{r}} \quad$ Radiation impulse response function $\left(\mathrm{kg} / \mathrm{s}^{2}\right)$

$k_{\mathrm{SS}} \quad$ Dimensionless value used to describe impact force (Shiffman and Spencer) (-)

$m \quad$ Body mass $(\mathrm{kg})$

$m_{\mathrm{a}} \quad$ Added mass $(\mathrm{kg})$

$m_{\mathrm{a}_{\infty}} \quad$ High-frequency limit of the added mass $(\mathrm{kg})$

$m_{\text {sup }} \quad$ Supplementary mass $(\mathrm{kg})$

$n_{f} \quad$ Number of frequencies (-)

$j \quad$ Imaginary unit

$p \quad$ Pressure $\left(\mathrm{bar}=10^{5} \mathrm{~Pa}\right)$

$p_{\text {abs }} \quad$ Absorbed power (W)

$r \quad$ Radial coordinate $(\mathrm{m})$

$R \quad$ Radius of hemisphere (m)

$S \quad$ Spectrum $\left(\mathrm{m}^{2} \mathrm{~s}\right)$

$t \quad$ Time (s)

$T_{\mathrm{p}} \quad$ Peak period (s)

$U \quad$ Entry velocity $(\mathrm{m} / \mathrm{s})$

$z \quad$ Vertical coordinate $(\mathrm{m})$ 
$z_{A \text {,sign }} \quad$ Significant amplitude of the buoy position (m)

$\beta \quad$ Deadrise angle $\left({ }^{\circ}\right.$ or $\left.\mathrm{rad}\right)$

$\zeta \quad$ Water elevation $(\mathrm{m})$

$\rho \quad$ Mass density of fluid $\left(\mathrm{kg} / \mathrm{m}^{3}\right)$

$\omega \quad$ Angular frequency ( $\mathrm{rad} / \mathrm{s})$

$\phi_{\mathrm{z}} \quad$ Phase angle of the buoy position (rad)

$\sigma \quad$ Spectral width parameter (-)

\section{Subscripts}

A Amplitude

s, sign Significant

\section{Introduction}

Wave energy is a renewable energy source that is becoming one of the players in the green energy market. Several wave energy converters (WECs) have been invented, among them point absorbers. These devices consist of oscillating, floating bodies with dimensions that are much smaller than the incident wave lengths. The bodies generally have a higher natural frequency than the incident wave frequencies and are therefore often tuned to the characteristics of the incident waves to augment power absorption. This tuning increases the body motion and consequently also the probability of it rising out of the water. When they re-enter the water, the buoys may be subjected to bottom slamming, which is typically associated with large impact pressures and forces. Slamming pressures are very localized in space and time. They are higher and more markedly peaked for smaller (local) deadrise angles and for larger drop heights, which implies larger impact velocities.

So far, research on point absorbers has mainly been focused on power absorption maximisation, for example by optimising the buoy shape and improving the control strategy. In order to determine an efficient practical tuning strategy and an optimal shape, however, slamming considerations need to be taken into account as well.

Figure 1 presents a schematic view of a conical point absorber subjected to water impact. The deadrise angle $\beta$ is the angle between a meridian of the body surface and the horizontal free water surface. When the point absorber penetrates the water, the water surface is no longer planar; it rises along the body surface. If the fluid is assumed to be incompressible, the law of conservation of mass requires that the volume above $z=0$ equals the displaced volume for $z \leq 0$. A jet flow is noticed that generally ends in a spray. The peak pressures occur in the outer domain, close to the spray roots. The pressure in the jet flow is very close to atmospheric pressure. For this reason, the rise in water level is very often modelled in a simplified way, focussing on the outer domain and neglecting the jet stream and spray roots (inner domain).

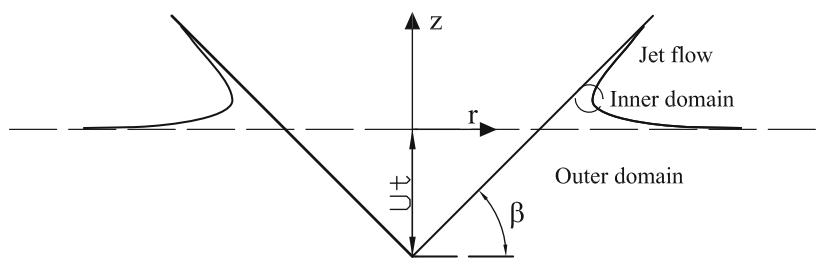

Fig. 1 Schematic of an impacting body

Slamming phenomena may cause local plastic deformation of the material, and have resulted in ship losses in extreme load cases [1]. However, both the extreme load cases and the operational conditions under which regular bottom slamming occurs, resulting in fatigue of the material, are important. Hence, it is important to assess how the occurrence probability of slamming depends on the wave climate, power take-off (PTO) and control system. For completeness, we should mention that bottom slamming is not only of importance in point absorber design; it is also important in relation to lateral slamming (wave slamming) of the buoys. The work of Wienke and Oumeraci [2], who experimentally investigated impact forces on slender cylinders due to plunging breaking waves, can be used as a first approximation of wave slamming forces on point absorbers.

In this work, we first illustrate the influence of slamming restrictions on the power absorption. A brief literature review of methods used to calculate the impact loads on cones and hemispheres is then presented. Finally, the emergence occurrence probabilities and the distributions of impact velocities and forces will be given for several examples.

\section{PTO control to decrease bottom slamming}

The occurrence probability of slamming and the associated impact loads can be decreased by influencing the control parameters of the buoy. Either the external damping applied to the buoy to extract power can be increased, the buoy can be detuned, or a combination of both can be applied. However, these measures result in power absorption losses, as will be illustrated in this section. Three shapes are considered: two cones with deadrise angles of $45^{\circ}$ and $30^{\circ}$, respectively, and a hemisphere. All bodies have a cylindrical upper part that is submerged by $0.50 \mathrm{~m}$ in the equilibrium position. The waterline diameter, $D$, is $5.00 \mathrm{~m}$, as indicated in Fig. 2. The equilibrium draft is $3.00 \mathrm{~m}$ for the $45^{\circ}$ cone and the hemisphere, and it is $1.94 \mathrm{~m}$ for the $30^{\circ}$ cone. The shapes and their corresponding masses are presented in Fig. 2. In practice, the edges at the transition between the conical and cylindrical parts are preferably rounded to reduce turbulence effects. 


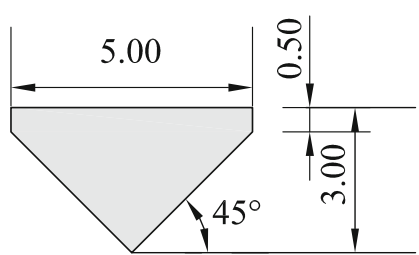

$\mathrm{m}=26.2$ ton

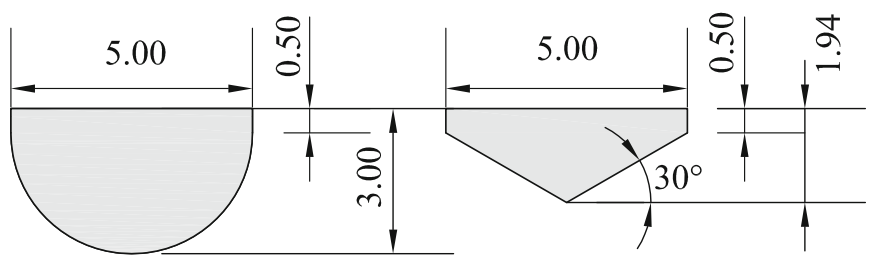

$\mathrm{m}=19.3$ ton

Fig. 2 Test shapes—submerged part in equilibrium: cone with deadrise angle of $45^{\circ}$, cone with deadrise angle of $30^{\circ}$, and hemisphere (dimensions in $\mathrm{m}$ )

Three sea states are defined: (1) $H_{\mathrm{s}}=1.25 \mathrm{~m}-T_{\mathrm{p}}=$ $5.98 \mathrm{~s}$, (2) $H_{\mathrm{s}}=2.75 \mathrm{~m}-T_{\mathrm{p}}=7.78 \mathrm{~s}$, (3) $H_{\mathrm{s}}=4.25 \mathrm{~m}$ $-T_{\mathrm{p}}=9.10 \mathrm{~s}$, where $H_{\mathrm{s}}$ is the significant wave height and $T_{\mathrm{p}}$ is the peak period. The first sea state represents a rather small wave, which can be regarded as a minimum threshold to produce electricity. In the second sea state the significant wave height instead has the order of magnitude of a design wave, and most likely has a high probability of occurrence in the areas developers are currently focussing on. It is assumed that the point absorbers are still in operation in the third, more energetic sea state. In storm conditions, however, point absorber devices generally stop producing electricity and switch to a safety mode in which the point absorbers are protected against bottom slamming or breaking wave slamming. This can be realized by completely submerging the buoys or by lifting them up to a certain level above the water surface [3].

The wave spectrum is determined using the parameterized JONSWAP spectrum [4] with a peak enhancement factor $\gamma=3.3$.

Employing linear theory, the equation of motion for the buoy in monochromatic incident waves can be expressed as:

$-\omega^{2}\left(m+m_{\mathrm{a}}+m_{\text {sup }}\right) \hat{z}+j \omega\left(b_{\text {ext }}+b_{\text {hyd }}\right) \hat{z}+k \hat{z}=\hat{F}_{\text {ex }}$.

The position of the buoy is given by $z=\operatorname{Re}\left(\hat{z} e^{j \omega t}\right)$, where $\omega$ is the angular frequency, $j$ is the imaginary unit, $t$ is the time, and $\hat{z}=z_{A} e^{j \phi_{z}}$ is the complex amplitude of $z$. The mass of the buoy is indicated by the symbol $m$, and the hydrostatic restoring coefficient by $k$. The frequency-dependent hydrodynamic coefficients of added mass and damping are represented by $m_{\mathrm{a}}$ and $b_{\text {hyd }}$, respectively. The complex amplitude of the heave exciting force is denoted by $\hat{F}_{\text {ex }}$. The hydrodynamic parameters $m_{\mathrm{a}}, b_{\text {hyd }}$ and $\hat{F}_{\text {ex }}$ are calculated with the boundary element method (BEM) software WAMIT [5]. A linear external damping coefficient, $b_{\text {ext }}$, simulates the PTO. A tuning force proportional to the acceleration has been implemented by means of the term with the supplementary mass, $m_{\text {sup }}$ [6]. The introduction of the supplementary mass enables a practical implementation of phase control in a linear model. A schematic

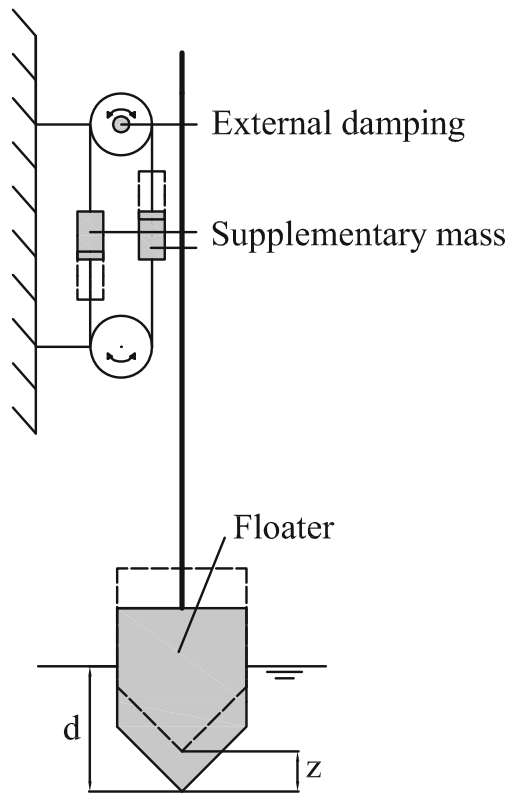

Fig. 3 Schematic representation of a heaving point absorber with a supplementary mass and external damping

representation is given in Fig. 3. By applying the supplementary mass to both sides of a rotating belt, the inertia of the device can be varied without changing the draft of the buoy. The tuning force could also be delivered by the generator, but this approach is discouraged, particularly when the tuning force required is much larger than the damping force, as discussed in Sect. 4. Phase control may also be achieved with a flywheel mechanically coupled to the buoy's vertical motion, or with latching control [7, 8].

Using the superposition principle, the time-averaged power absorption, $P_{\text {abs }}$, can be obtained:

$P_{\mathrm{abs}}=\sum_{i=1}^{n_{\mathrm{f}}} \frac{1}{2} b_{\mathrm{ext}} \omega_{i}^{2} z_{A i}^{2}$,

where $n_{f}$ is the number of frequencies considered $\left(n_{f}=150\right)$. The maximum panel size of the body mesh is $0.15 \mathrm{~m}$, which is sufficiently small compared to the wavelength corresponding to the components with the highest frequencies $\left[f_{i} \in(0.035 \mathrm{~Hz} \ldots 0.333 \mathrm{~Hz})\right]$. 
Generally, the external damping force and tuning force are optimized in order to maximize the power absorption $[9,10]$. To avoid excessive slamming, slamming constraints are taken into account during the optimisation procedure, which requires that the significant amplitude of the position of the buoy relative to the free water surface, $\zeta$, is limited to a fraction $\alpha$ of the buoy draft:

$(z-\zeta)_{A, \text { sign }}<\alpha d$.

If the spectrum of the relative position is defined as $S_{i}=\left(z_{i}-\zeta_{i}\right)^{2}{ }_{A} /(2 \Delta f)$, the significant amplitude of the relative buoy position is obtained with

$(z-\zeta)_{A, \text { sign }}=2 \sqrt{\sum_{i}^{n_{f}} S_{i} \Delta f .}$

The slamming restriction in Eq. 3 must be fulfilled for each sea state. This may necessitate adapting the control parameters $m_{\text {sup }}$ and $b_{\text {ext }}$ compared to unconstrained conditions. The optimal control parameters are obtained with an exhaustive search method. The choice of the slamming restriction factor $\alpha$ in Eq. 3 has a direct impact on the probability of emergence occurring. When $\alpha$ is chosen to be equal to 1 , emergence events will still be allowed for the top $13.5 \%$ of the highest waves, assuming that the wave and body displacement amplitudes are Rayleigh distributed. In small waves, the slamming criterion does not influence the optimal values of the control parameters. However, for higher waves, less optimal values of the control parameters $b_{\text {ext }}$ and $m_{\text {sup }}$ must be chosen in order to fulfill the slamming criterion. This is illustrated for the $45^{\circ}$ cone in Figs. 4, 5 and 6, which show the time-averaged absorbed power as a function of the control parameters $b_{\text {ext }}$

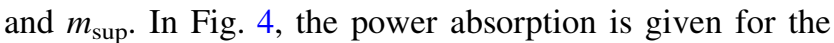
second sea state $\left(H_{\mathrm{s}}=2.75 \mathrm{~m}-T_{\mathrm{p}}=7.78 \mathrm{~s}\right)$, together with three slamming contour lines with $\alpha$ values of 0.75 , 1.00 and 1.50 , respectively. The area enclosed by the contour lines has to be avoided to fulfill the slamming restriction, resulting in less power absorption for stricter slamming constraints. For the least stringent constraint $(\alpha=1.50)$, the maximum time-averaged power absorption in the remaining area is $115 \mathrm{~kW}$. This drops to $96 \mathrm{~kW}$ for the intermediate constraint $(\alpha=1.00)$, and the maximum absorbed power equals $79 \mathrm{~kW}$ for the most stringent constraint $(\alpha=0.75)$. The maximum values are indicated with black circles.

Two velocity contour lines of 2 and $4 \mathrm{~m} / \mathrm{s}$ are also shown in Fig. 4. These lines represent equally significant values of the vertical buoy velocity relative to the vertical wave velocity. The significant amplitude of the relative velocity could also be used to formulate a slamming constraint instead of the relative displacement amplitude. The latter restriction is directly linked to the slamming

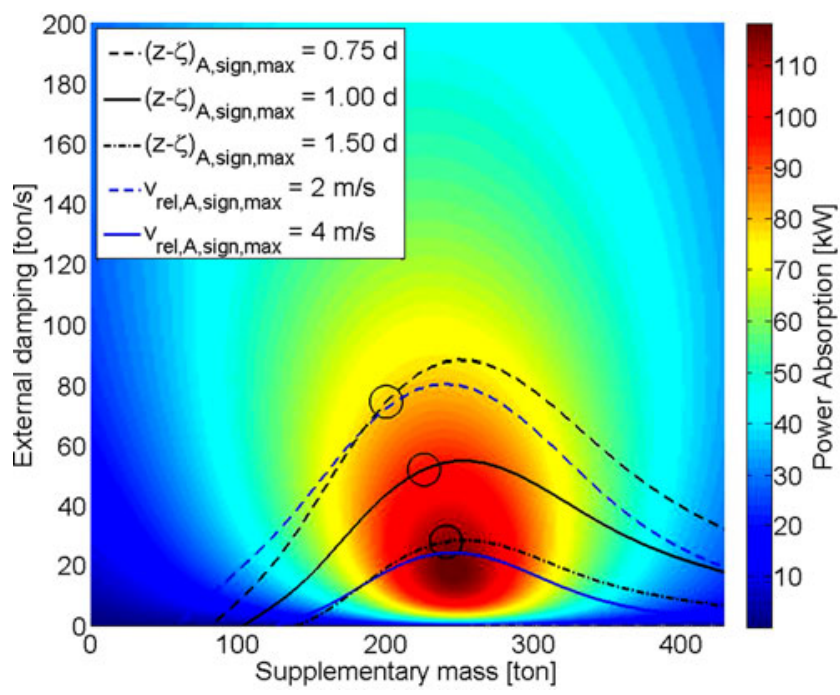

Fig. 4 Power absorbed (kW) as a function of the control parameters, $b_{\text {ext }}$ and $m_{\text {sup }}$, by the $45^{\circ}$ cone for sea state $2\left(H_{\mathrm{s}}=2.75 \mathrm{~m}-T_{\mathrm{p}}=\right.$ $7.78 \mathrm{~s}$ ), along with slamming restrictions (contour lines)

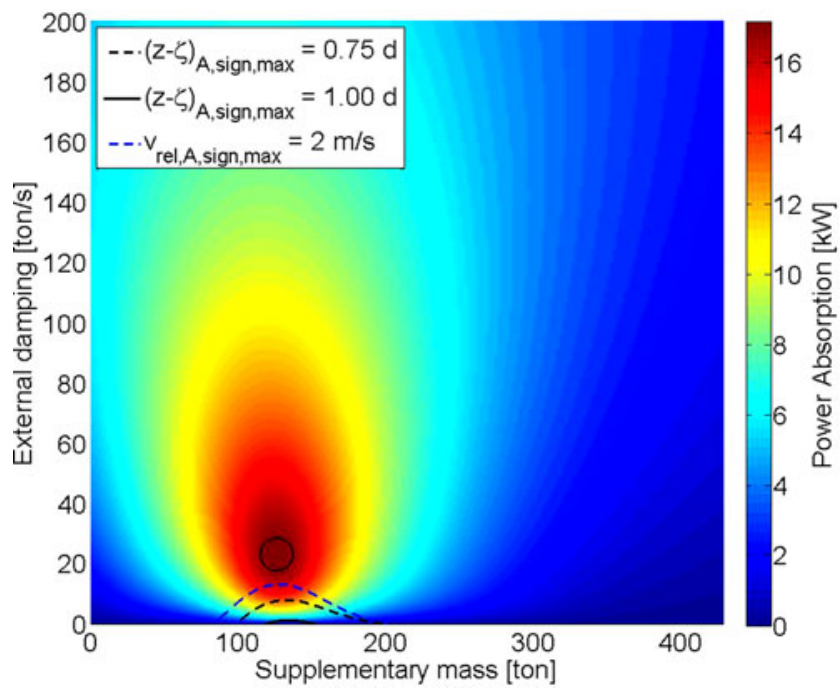

Fig. 5 Power (kW) absorbed as a function of the control parameters, $b_{\text {ext }}$ and $m_{\text {sup }}$, by the $45^{\circ}$ cone for sea state $1\left(H_{\mathrm{s}}=1.25 \mathrm{~m}-T_{\mathrm{p}}=\right.$ $5.98 \mathrm{~s}$ ), along with slamming restrictions (contour lines)

occurrence probability, whereas the relative velocity constraint is related to the pressures and forces.

It can be observed from the graph that the slamming restrictions are mainly fulfilled by increasing the damping, and only to a lesser extent by decreasing the supplementary mass. Table 1 presents the time-averaged power absorption values for the three shapes per sea state and for different levels of the slamming restriction factor $\alpha$. The power absorption numbers presented are the maximum values that can be obtained when satisfying the slamming restriction, according to Eq. 3. The values that could be theoretically 


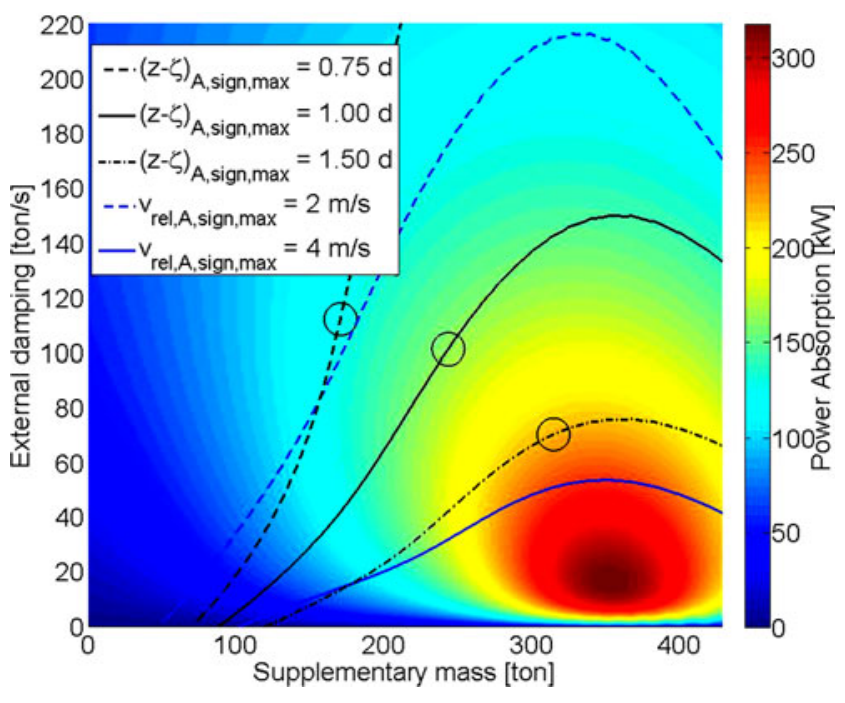

Fig. 6 Power $(\mathrm{kW})$ absorbed as a function of the control parameters, $b_{\text {ext }}$ and $m_{\text {sup }}$, by the $45^{\circ}$ cone for sea state $3\left(H_{\mathrm{s}}=4.25 \mathrm{~m}-T_{\mathrm{p}}=\right.$ $9.10 \mathrm{~s}$ ), along with slamming restrictions (contour lines)

Table 1 Power absorbed $(\mathrm{kW})$ by the three shapes for the three sea states and for different slamming restrictions

\begin{tabular}{|c|c|c|c|c|c|c|c|c|c|}
\hline \multirow[t]{3}{*}{$\alpha$} & \multicolumn{9}{|c|}{ Sea state } \\
\hline & \multicolumn{3}{|c|}{$45^{\circ}$ cone } & \multicolumn{3}{|c|}{ Hemisphere } & \multicolumn{3}{|c|}{$30^{\circ}$ cone } \\
\hline & 1 & 2 & 3 & 1 & 2 & 3 & 1 & 2 & 3 \\
\hline 0.75 & 17 & 79 & 125 & 16 & 75 & 119 & 18 & 55 & 83 \\
\hline 1.00 & 17 & 96 & 162 & 16 & 91 & 155 & 18 & 72 & 110 \\
\hline 1.50 & 17 & 115 & 221 & 16 & 108 & 211 & 18 & 96 & 161 \\
\hline$\infty$ & 17 & 118 & 317 & 16 & 111 & 302 & 18 & 121 & 326 \\
\hline
\end{tabular}

absorbed if no restrictions are included $(\alpha=\infty)$ are also shown. However, these values and those associated with weak slamming constraints do not always represent practically achievable solutions. Furthermore, the power absorption numbers do not take into account losses due to mechanical friction, turbulent losses, turbine and generator losses, or any other losses in the conversion system, and are thus not equal to the electrical power produced.

Figure 5 shows the power absorption for the first sea state $\left(H_{\mathrm{s}}=1.25 \mathrm{~m}-T_{\mathrm{p}}=5.98 \mathrm{~s}\right)$. None of the slamming constraints exerts an influence on the optimal tuning and damping parameters. The maximum power absorption value $(17 \mathrm{~kW})$ can be achieved while slamming phenomena seldom occur.

Figure 6 presents the power absorption and slamming contour lines for the most energetic sea state $\left(H_{\mathrm{s}}=\right.$ $\left.4.25 \mathrm{~m}-T_{\mathrm{p}}=9.10 \mathrm{~s}\right)$. Theoretically, the dark red coloured area, the resonance zone, leads to the highest power production. However, this zone requires very large tuning forces on the one hand and is associated with extremely

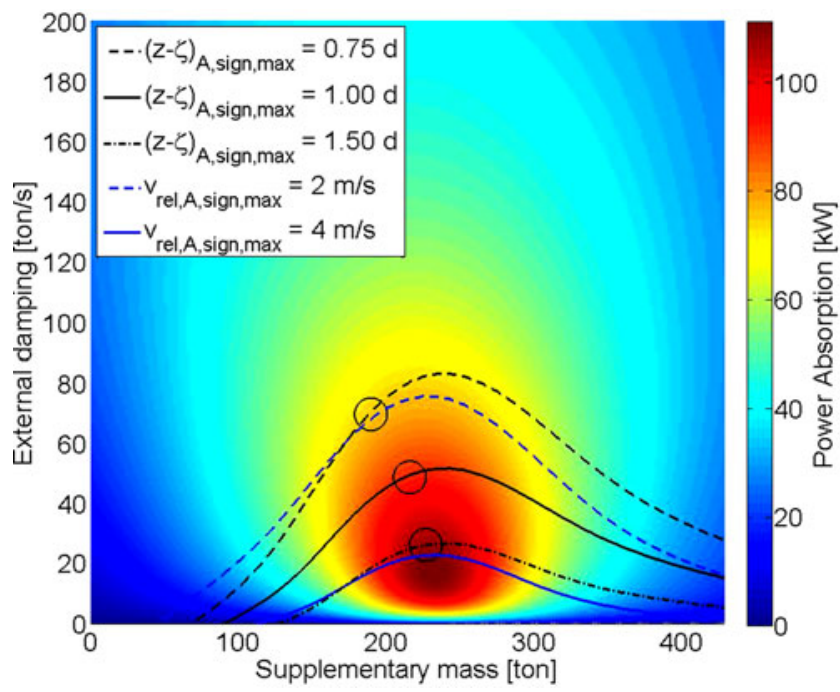

Fig. 7 Power absorbed (kW) as a function of the control parameters, $b_{\text {ext }}$ and $m_{\text {sup }}$, by the hemisphere for sea state $2\left(H_{\mathrm{s}}=2.75 \mathrm{~m}-T_{\mathrm{p}}=\right.$ $7.78 \mathrm{~s}$ ), along with slamming restrictions (contour lines)

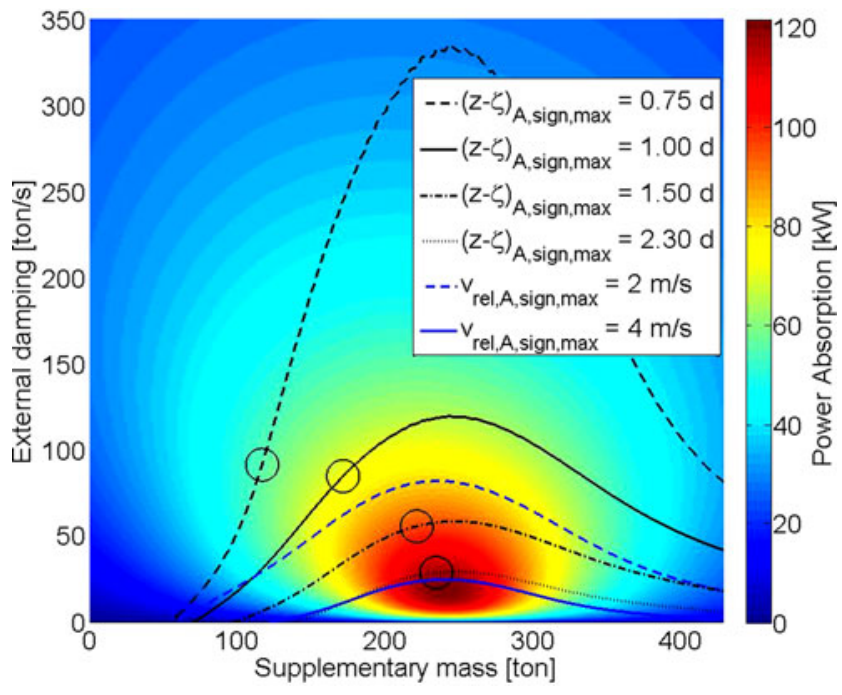

Fig. 8 Power absorbed $(\mathrm{kW})$ as a function of the control parameters, $b_{\text {ext }}$ and $m_{\text {sup }}$, by the $30^{\circ}$ cone for sea state $2\left(H_{\mathrm{s}}=2.75 \mathrm{~m}-T_{\mathrm{p}}=\right.$ $7.78 \mathrm{~s}$ ), along with slamming restrictions (contour lines)

high buoy displacement and velocity amplitudes on the other. Therefore, for practical cases, this zone is not the target area in large waves. In order to satisfy the restrictions, not only must the damping be increased but the tuning forces must also be considerably decreased. The absorbed power is largely dependent on the level of slamming that is allowed. The optimal power values drop from 221 to 162 and $125 \mathrm{~kW}$, respectively, for the weakest to the intermediate and most stringent restrictions.

For comparison, the power absorption in the intermediate sea state $\left(H_{\mathrm{s}}=2.75 \mathrm{~m}-T_{\mathrm{p}}=7.78 \mathrm{~s}\right)$ is shown in Figs. 7 and 8 for the hemisphere and the $30^{\circ}$ cone, 
respectively. The results for the hemisphere are very similar to those for the $45^{\circ}$ cone, although there is a slight advantage for the $45^{\circ}$ cone. The performance of the latter is between 4 and $8 \%$ better than that of the hemisphere for the same slamming conditions, as illustrated by the power absorption figures in Table 1. Much larger differences (between 15 and 30\%) are observed for the $30^{\circ}$ cone. For $\alpha$ equal to 1.5 , the power absorption is $96 \mathrm{~kW}$; for $\alpha$ values of 1 and 0.75 , the power absorption drops to 72 and $55 \mathrm{~kW}$, respectively (see Table 1). For the same $\alpha$ values as for the other shapes, the constraints are much stronger for the $30^{\circ}$ cone shape, since the draft $d$ is smaller. Because of its small draft, the buoy will easily lose contact with the water surface and slam. This is why the slamming constraint needs to be stricter in this case to allow the same level of slamming as for the other shapes, which is equivalent to using the same value of $\alpha$. Alternatively, if the same absolute restriction is imposed on the relative significant position of the buoy, i.e. the same value of $\alpha \cdot d$, the $30^{\circ}$ cone will emerge much more frequently than the other shapes. However, the power absorption will be of the same order of magnitude or even slightly higher, since it benefits from large exciting forces due to its small draft. An example is given for $\alpha=2.3$ for the $30^{\circ}$ cone. This value of $\alpha$ implies a restriction of approximately $4.5 \mathrm{~m}$ on the maximum relative significant amplitude of the buoy position and corresponds to an $\alpha$ value of 1.5 for the $45^{\circ}$ cone and hemisphere. The power absorption in this case is $117 \mathrm{~kW}$ for the $30^{\circ}$ cone compared to 115 and $106 \mathrm{~kW}$ for the $45^{\circ}$ cone and hemisphere, respectively. These numbers have to be treated with caution, since this example represents a case where extremely high slamming rates and buoy motions occur, as will be shown later, which violate the assumptions of linear theory. Contrary to Figs. 4 and 7 for the $45^{\circ}$ cone and hemisphere, respectively, the two velocity contour lines in Fig. 8 enclose a relatively limited area compared to the displacement contour lines for the $30^{\circ}$ cone. Hence, when slamming constraints are formulated, based on the same velocity contour lines for the three shapes, this may result in a weaker restriction for the $30^{\circ}$ cone compared to constraints based on the same contour lines of relative displacement.

The control strategy used in this example optimizes the tuning and damping coefficients ( $m_{\text {sup }}$ and $\left.b_{\text {ext }}\right)$ for a certain sea state and keeps them fixed during that sea state. This offers the practical benefit of a relatively simple control strategy. With a more complex (wave-to-wave) strategy, the control can be adapted to the instantaneous water elevation at the position of the buoy and/or the motion parameters of the buoy. Slamming phenomena can then be reduced, for example by decreasing the immediate floater displacement and velocity at time instants where they might become very large. In this way, slamming can be diminished without deteriorating the power absorption too much in instantaneous small and intermediate waves within a certain sea state. Compared to this method, the slamming restrictions of the fixed-coefficients control strategy are rather conservative and consequently so are the estimated drops in power absorption. However, a wave-towave control strategy is a lot more difficult to realise in practice: a particularly reliable control system is required, as well as very reliable predictions of the immediate water elevation at the position of the buoy and the motion parameters of the buoy.

How strict a slamming constraint needs to be depends on the impact loads to which the buoys can be subjected and the number of slamming events that can be tolerated by the buoy structure. For this reason, the next sections will focus on the impact loads on buoy shapes and on the occurrence probabilities of emergence events.

\section{Slamming loads}

One of the pioneers in slamming research is Von Karman [11], who studied water impacts in order to estimate the pressure on hydroplane floats during sea landings. Further research was subsequently carried out by Wagner [12]. He adapted the Von Karman solution by taking into account the rise in the water level on the body in a simplified way. Wagner mainly analysed slamming effects on two-dimensional solid bodies. The shapes of these bodies can be approximated by growing flat plates, which implies that the Wagner method assumes small deadrise angles in the range of $4-20^{\circ}$ [13]. Furthermore, Wagner's theory assumes the potential flow of an incompressible fluid and neglects gravitational effects. The blunt body approximation allowed Wagner to use analytical expressions for the velocity potential and to formulate relatively simple formulae for the pressure distribution on wedges. Based on this principle, Chuang [14], Toyama [15] and Faltinsen and Zhao [16] extended Wagner's asymptotic theory for axisymmetric bodies by approximating the body shapes with rigid, flat discs that have an extending radius. Chuang developed an analytical expression for the pressure distribution on a cone with a small deadrise angle. In 1997, Faltinsen and Zhao [16] presented a theory for the entry of hemispheres and cones with small (local) deadrise angles into water based on the assumptions behind Wagner's theory. Scolan and Korobkin [17] presented analytical solutions for three-dimensional bodies obtained with the inverse Wagner method. Nowadays, the Wagner principle is still used in some numerical solvers, e.g. that of Peseux et al. [1]. With the current evolution in computer power, CFD models are also increasingly used for simulations of slamming phenomena [18-22]. Slamming pressures on 
typical point absorber shapes have been experimentally investigated by means of drop tests in [23, 24].

In the next paragraphs, a brief nonexhaustive overview of literature results on slamming loads will be given and applied to the typical point absorber shapes and dimensions shown in Fig. 2. The hydrodynamic impact force can be expressed as:

$F_{3}=\frac{\mathrm{d}\left(\mathrm{m}_{\mathrm{a}_{\infty}} \mathrm{U}\right)}{\mathrm{d} t}=m_{\mathrm{a}_{\infty}} \frac{\mathrm{dU}}{\mathrm{d} t}+\frac{\mathrm{dm}_{\mathrm{a}_{\infty}}}{\mathrm{d} t} U$,

where $m_{\mathrm{a}_{\infty}}$ is the infinite frequency limit of the added mass. If a constant entry velocity is assumed, the first term in Eq. 5 vanishes.

Shiffman and Spencer [25] developed a theoretical formula, as expressed in Eq. 6, for the impact force on a cone by approximating the cone shape with an ellipsoid:

$F_{3 \text { cone }}=\frac{3 m_{\mathrm{a}_{\infty}}}{U t\left(1+\left(m_{\mathrm{a}_{\infty}} / m\right)\right)^{3}} U^{2}$,

where $m$ is the mass of the cone and $U$ is the initial entry velocity. The added mass for infinite frequency is expressed as: $m_{\mathrm{a}_{\infty}}=k_{\mathrm{ss}}(\beta) \rho\left(U t \tan \left(\frac{\pi}{2}-\beta\right)\right)^{3}$, where $k_{\mathrm{ss}}$ is a nondimensional value between 0 and 3 that depends on the deadrise angle. For a cone with a deadrise angle $\beta=20^{\circ}, 30^{\circ}$ and $45^{\circ}, k_{\mathrm{ss}}$ is $2.24,1.6$ and 1.4 , respectively. Shiffman and Spencer stated that Eq. 6 is a good approximation up to the penetration depth where $F_{3}$ attains its maximum value. This theory is based on the similitude of the flow at different time instants, and thus assumes an approximately constant entry velocity. This implies that the mass of the buoy should be much larger than the mass of the displaced water. Consequently Eq. 6 can be approximated with:

$F_{3 \text { cone }}=3 k_{\mathrm{ss}} \rho \tan ^{3}\left(\frac{\pi}{2}-\beta\right) U^{4} t^{2}$.

Battistin and Iafrati [26] and Kleefsman et al. [20] found a good correspondence between their numerical results for a cone with a constant entry velocity and Eq. 7 of Shiffman and Spencer.

Miloh [27] analysed the impact on a sphere that satisfies the exact body boundary conditions. Using a wetting coefficient, $C_{\mathrm{w}}=1+\frac{\zeta}{U t}$, of 1.327 , he suggests a force $F_{3}$ for small entry depths and a constant entry velocity of

$$
\begin{aligned}
F_{3 \text { hemisphere }}= & 0.5 \rho \pi R^{2} U^{2}\left(5.5\left(\frac{U t}{R}\right)^{(1 / 2)}-4.19\left(\frac{U t}{R}\right)\right. \\
& \left.-4.26\left(\frac{U t}{R}\right)^{(3 / 2)}\right) .
\end{aligned}
$$

Faltinsen and Zhao [16] presented analytical formulae based on the classical Wagner theory for $F_{3}$ by integrating the pressure while accounting for the nonpermanent flow around the expanding disc. Since a constant entry velocity is assumed, the first term in Eq. 5 drops out, resulting in Eqs. 9 and 10 for a cone and hemisphere, respectively [16]:

$$
\begin{aligned}
& F_{3 \text { cone }}=256 \rho \frac{t^{2} U^{4}}{(\pi \tan \beta)^{3}} \\
& F_{\text {3hemisphere }}=6 \sqrt{3} \rho \sqrt{U^{5} t R^{3}} .
\end{aligned}
$$

These formulae are only valid for small entry depths for the hemisphere and small deadrise angles for the cone shape, due to the simplified body boundary condition. A generalization of Wagner's solution to larger local deadrise angles has been proposed by Zhao et al. for arbitrary two-dimensional bodies [28], and has been extended for axisymmetric bodies in $[16,29]$ and for arbitrary threedimensional bodies in [30]. The main difference from the classical Wagner method is that the exact body boundary condition is satisfied.

Figure 9 shows several predictions of the slamming force coefficient $C_{\mathrm{s}}=F_{3} / 0.5 \rho \pi R^{2} U^{2}$ on a sphere. The black dashed line represents Eq. 10 of Faltinsen. The formula derived by Miloh is given as a black solid line. The analytical expressions are compared with experimental results from Moghisi and Squire [31] (grey dash-dotted line), with numerical data from Faltinsen and Zhao [16] obtained using the generalized Wagner theory (grey dashed line), and with the results of Battistin and Iafrati [26] (grey solid line). In the numerical approaches, a constant entry velocity is assumed, the exact body boundary conditions are fulfilled, the uprising of the water is accounted for, and the slamming force coefficients are obtained by pressure integration. The asymptotic theory clearly overestimates the force by a large margin after the very earliest stage of submergence. The numerical results $[16,26]$ and the analytical formula from Miloh correspond quite well with the experimental values of Moghisi and Squire.

Figure 10 compares the impact force on a hemisphere $(R=2.5 \mathrm{~m})$ with those for two cones with deadrise angles of $30^{\circ}$ and $45^{\circ}$ for a drop height of $2 \mathrm{~m}$. Note the large force magnitude (up to almost $500 \mathrm{kN}$ ) for the hemisphere. Equation 6 of Shiffman and Spencer corresponds well with the approximation in Eq. 7 during the initial impact phase. However, a discrepancy gradually appears that becomes quite large at the maximum impact force. The maximum value of the hydrodynamic load on the hemisphere is reached very quickly after submergence, at $U t=0.41 \mathrm{~m}$, after which it smoothly decreases. The maximum level for the $30^{\circ}$ cone is attained at a submergence of $0.87 \mathrm{~m}$ and for the $45^{\circ}$ cone at $1.75 \mathrm{~m}$. Obviously the deadrise angle of the cone has a huge influence on the magnitude and rise time of the impact force.

It must be noted that hydroelastic effects may become important when the deadrise angle of the body is small, the 


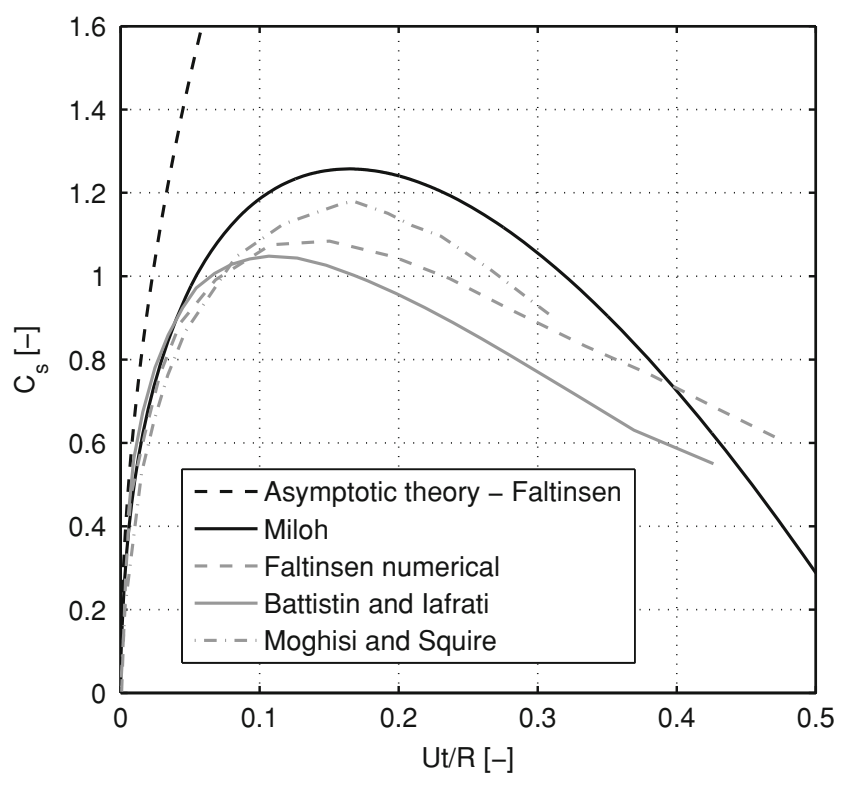

Fig. 9 Slamming force coefficient $C_{\mathrm{s}}$ on a hemisphere versus the dimensionless time $U t / R$

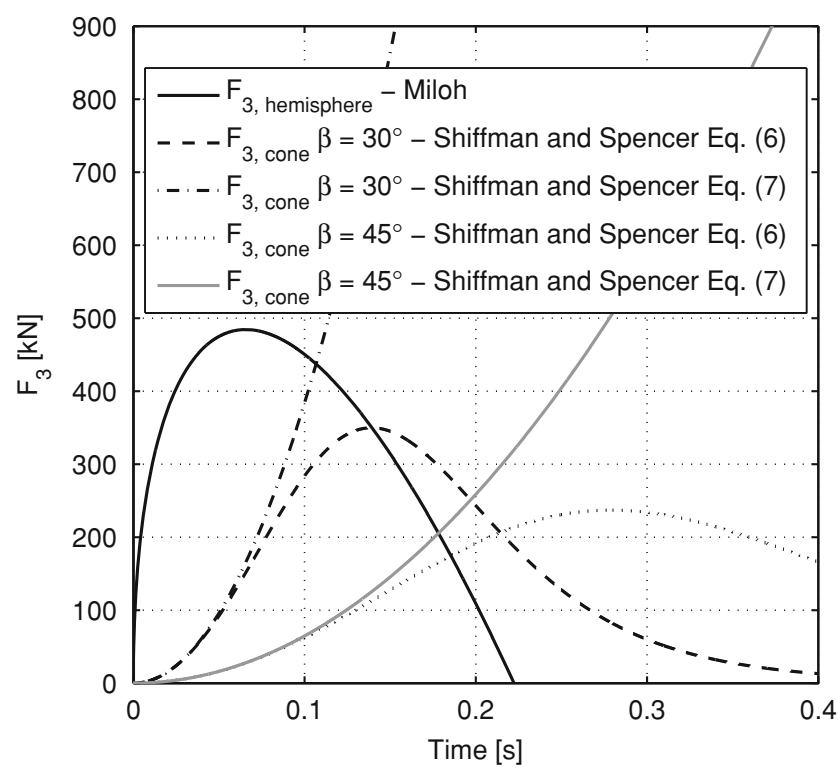

Fig. 10 Forces on a hemisphere and two cones $\left(\beta=30^{\circ}\right.$ and $\left.45^{\circ}\right)$ with $R=2.5 \mathrm{~m}$ and a drop height of $2 \mathrm{~m}$, i.e. $U=6.3 \mathrm{~m} / \mathrm{s}$; $m_{\text {hemisphere }}=42.5$ ton, $m_{\text {cone }} 45^{\circ}=26.2$ ton, $m_{\text {cone }} 30^{\circ}=19.3$ ton

impact velocity is large, and the value of the highest natural period of the local structure is large $[32,33]$. When hydroelasticity is significant, the maximum strains associated with the water impact should be studied directly, rather than deriving them from design pressures. The hydroelastic behaviour of point absorber structures is not considered in this paper.

\section{Probability of emergence}

For design purposes, it is not only important to know the magnitude of the slamming loads that are associated with certain impact velocities, but it is also essential to examine the occurrence probabilities of these impacts. This aspect is investigated with a time domain model, by simulating the point absorber motions in irregular waves and storing the information on each slamming event. For the three sea states and the point absorber shapes defined in Sect. 2, simulations are run with a linear time domain model. Based on the equations of Cummins [34], the equation of motion for a heaving point absorber can be expressed in the time domain as:

$$
\begin{aligned}
{[m} & \left.+m_{\mathrm{a}, \infty}+m_{\mathrm{sup}}\right] \frac{d^{2} \mathrm{z}(\mathrm{t})}{\mathrm{d} t^{2}}+b_{\mathrm{ext}} \frac{\mathrm{dz}(\mathrm{t})}{\mathrm{d} t} \\
& +\int_{0}^{t} K_{\mathrm{r}}(t-\tau) \frac{\mathrm{dz}(\tau)}{\mathrm{d} \tau} \mathrm{d} \tau+k z(t)=F_{\mathrm{ex}}(t),
\end{aligned}
$$

where $m_{\mathrm{a}, \infty}$ is the high-frequency limit of the added mass and $K_{\mathrm{r}}(t)$ is the radiation impulse response function (IRF). The radiation IRF has been derived from the frequency domain hydrodynamic coefficient damping with the WAMIT F2T utility [5]. To compute the IRF, the hydrodynamic parameters must be evaluated for a wide frequency range. For this reason, the interval used for the frequency components $f_{i}$ is different from that used in Sect. 2, i.e. $f_{i} \in(0.008 \ldots 1.114 \mathrm{~Hz})$.

In order to solve Eq. 11 directly, the solution of the convolution integral has to be known at every time step, which may require considerable CPU time. Therefore, the impulse response function is approximated by a sum of exponential functions obtained with Prony's method, and the integro-differential equation is transformed into a system of ordinary differential equations [35].

Long-crested waves are generated with a duration of $10000 \mathrm{~s}$. This duration is considered to be long enough to study slamming phenomena. It contains 2011 waves for the first sea state, 1510 waves for the second sea state and 1333 waves for the third sea state. The simulations are performed with a very small time step $(\Delta t=0.02 \mathrm{~s})$, since CPU time was not an issue. The impact velocity when the body re-enters the water surface has been determined as well as the number of emergences per hour. In marine hydrodynamics, it is convenient to consider a minimum relative impact velocity to determine slamming occurrence probabilities. This threshold velocity is based on the impact pressures and forces. A general threshold velocity has not been considered in this case, since the impact loads are strongly dependent on the point absorber shape. Therefore, the probability of emergence has been determined, i.e. the 
chance of rising out of the water, rather than the slamming probability.

The peak load is derived for each shape from the impact velocity based on the expressions in Sect. 3. Equation 6 of Shiffman and Spencer was used for the conical shape and Eq. 8 of Miloh for the hemisphere.

Attention should be drawn to the fact that the assumptions of linear theory (small waves and small body motions) are violated when the buoy leaves the water. However, in irregular waves, the correspondence between linear theory and experiments is still satisfactory when the buoy is operating outside the resonance zone [36]. Since this is generally the case, the linear model can be used in an acceptable way to predict the emergence occurrence probability and to estimate the impact velocities of the buoy. To obtain more accurate results for the impact velocities, the use of a nonlinear time domain model is advised for future work, especially from the perspective of body mechanics rather than wave mechanics.

Figure 11 shows the number of emergence events per hour for the three slamming restrictions as a function of the impact velocity. These results are obtained from simulations with the $45^{\circ}$ cone-cylinder shape $\left(\mathrm{cc}-\beta=45^{\circ}\right)$ in the second sea state $\left(H_{\mathrm{s}}=2.75 \mathrm{~m}-T_{\mathrm{p}}=7.78 \mathrm{~s}\right)$. The contribution of the velocity of the surface elevation to the impact velocity is neglected in these calculations. Hence, the impact velocity is approximated by the buoy velocity at re-entry. A significant difference between the restrictions is observed in both the number of emergences and the magnitude of the impact velocity. The emergence occurrence probability is defined as the number of emergence events divided by the number of waves in the wavetrain. Figure 12 gives the hourly number of emergences as a function of the peak impact force corresponding to the estimated impact velocities, according to Eq. 6. This means that a constant impact velocity is assumed between the initial time $t_{0}$ and the time at which the maximum force occurs. This (conservative) assumption can be justified by noting the fact that the buoys have considerable mass. The influence of the slamming restrictions is even more pronounced for the impact forces, since a quadratic relationship exists between the impact velocity and the peak impact force. However, most of the emergences still occur with relatively small peak impact forces for the $45^{\circ}$ cone.

The results for the third sea state are similar to those for the second sea state, since the same level of slamming is allowed by applying the same restrictions. However, the power losses needed to fulfill these restrictions are much larger for the third sea state than for the second sea state, as one can see by comparing the power plots of Figs. 4 and 6.

In Figs. 13 and 14, the distributions for the impact velocity and peak impact load, obtained according to Eq. 8,

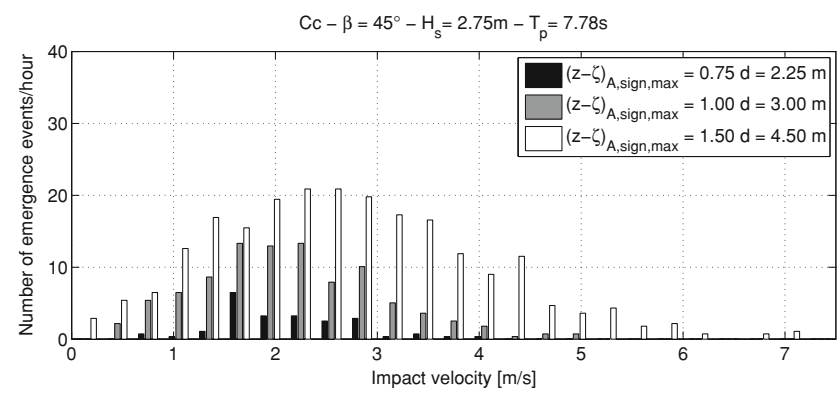

Fig. 11 Number of emergence events per hour as a function of the impact velocity for the $45^{\circ}$ cone, sea state: $H_{\mathrm{s}}=2.75 \mathrm{~m}, T_{\mathrm{p}}=7.78 \mathrm{~s}$

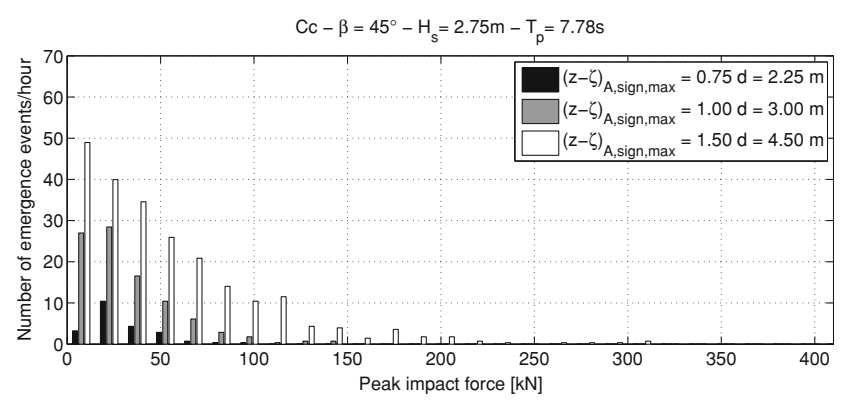

Fig. 12 Number of emergence events per hour as a function of the peak impact force for the $45^{\circ}$ cone, sea state: $H_{\mathrm{s}}=2.75 \mathrm{~m}$, $T_{\mathrm{p}}=7.78 \mathrm{~s}$

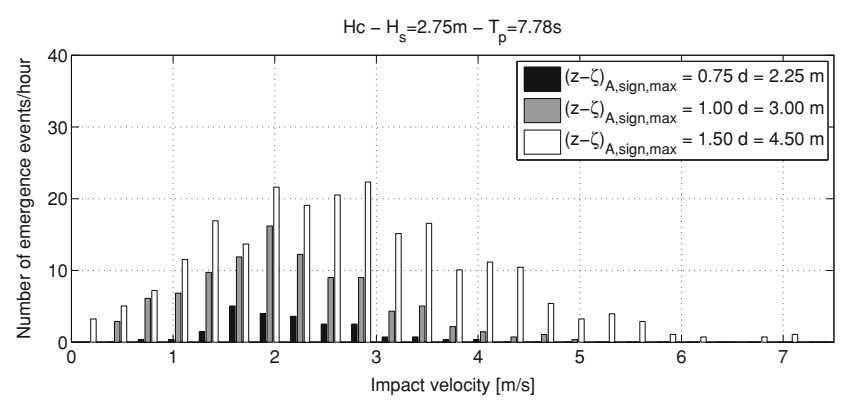

Fig. 13 Number of emergence events per hour as a function of the impact velocity for the hemisphere, sea state: $H_{\mathrm{s}}=2.75 \mathrm{~m}$, $T_{\mathrm{p}}=7.78 \mathrm{~s}$

are given for the hemisphere-cylinder shape (hc) in the second sea state $\left(H_{\mathrm{s}}=2.75 \mathrm{~m}-T_{\mathrm{p}}=7.78 \mathrm{~s}\right)$. As expected, Fig. 13, showing the velocity distribution of the hemisphere strongly resembles Fig. 11, which presents the impact velocities for the $45^{\circ}$ cone. Consequently, the total number of emergences per hour is almost the same in the two cases for the same $\alpha$ factors. However, the distribution of peak load is very different for each case. For the $45^{\circ}$ cone, most of the emergence events occur at small forces, whereas for the hemisphere the number of emergences at small impact forces is minor, and is compensated by a significant amount of emergences with higher impact 


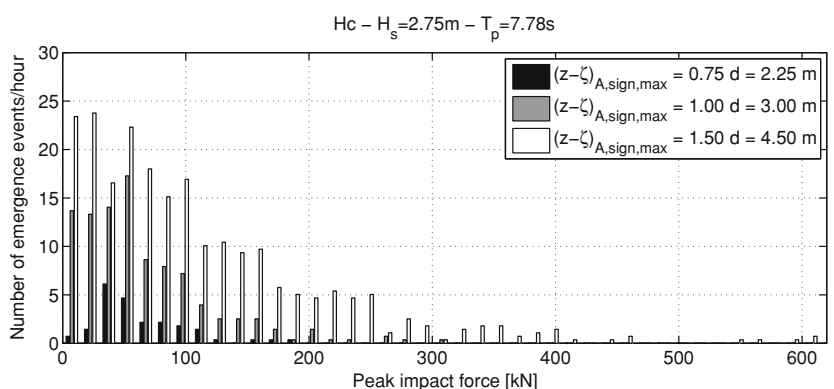

Fig. 14 Number of emergence events per hour as a function of the peak impact force for the hemisphere, sea state: $H_{\mathrm{s}}=2.75 \mathrm{~m}$, $T_{\mathrm{p}}=7.78 \mathrm{~s}$

forces. This is not surprising, since the ratio of the peak load on the hemisphere $(R=2.5 \mathrm{~m})$ to that on the $45^{\circ}$ cone is 2.0. This kind of graph can be used as an input for structural design processes. Extreme operational load cases in energetic waves need to be simulated as well as fatigue tests in (presumably) smaller waves, as the latter have a larger occurrence probability. If the occurrence probabilities of several sea states are known, e.g. they are derived from a scatter diagram, the yearly number of emergences and their corresponding impact forces can be calculated for the specific target location. The graphs are also useful for evaluating the control strategy with respect to slamming and adapting or optimizing it where necessary, taking into account the requirements of the structural designers. If the control is adapted to reduce slamming, power will be lost but the cost of manufacturing the buoys will benefit from it, and vice versa. As a consequence, an economic optimum needs to be found.

Figures 15 and 16 give the hourly number of emergence events as functions of the impact velocity and peak impact force, respectively, for the $30^{\circ}$ cone in the second sea state, i.e. $H_{\mathrm{s}}=2.75 \mathrm{~m}, T_{\mathrm{p}}=7.783 \mathrm{~s}$. For the same $\alpha$ values as before, the impact velocities are found to be a bit smaller than those for the $45^{\circ}$ cone. This is compensated by the larger peak forces on the $30^{\circ}$ cone, which are approximately a factor of 1.5 larger than those on the $45^{\circ}$ cone for the same values of impact velocity, according to Eq. 6 of Shiffman and Spencer.

Recall that applying the same $\alpha$ values in the formulation of the constraints implies much stricter slamming constraints for the $30^{\circ}$ cone, because its draft is considerably smaller. When the relative significant amplitude of the $30^{\circ}$ cone is limited to the same values as the $45^{\circ}$ cone and hemisphere, then emergence will obviously occur a lot more for the $30^{\circ}$ cone due to its small submergence. This is illustrated in Figs. 15 and 16 with the extra bars coloured in pale grey. They represent a restriction on the relative significant buoy amplitude of $2.30 \mathrm{~d}=4.47 \mathrm{~m}$. This limitation corresponds approximately to the constraint of the white bars in Figs. 11, 12, 13 and 14. Similarly, the white

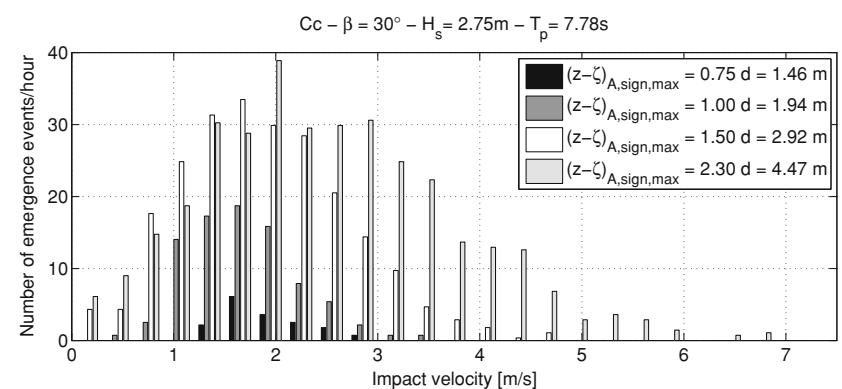

Fig. 15 Number of emergence events per hour as a function of the impact velocity for the $30^{\circ}$ cone, sea state: $H_{\mathrm{s}}=2.75 \mathrm{~m}, T_{\mathrm{p}}=7.78 \mathrm{~s}$

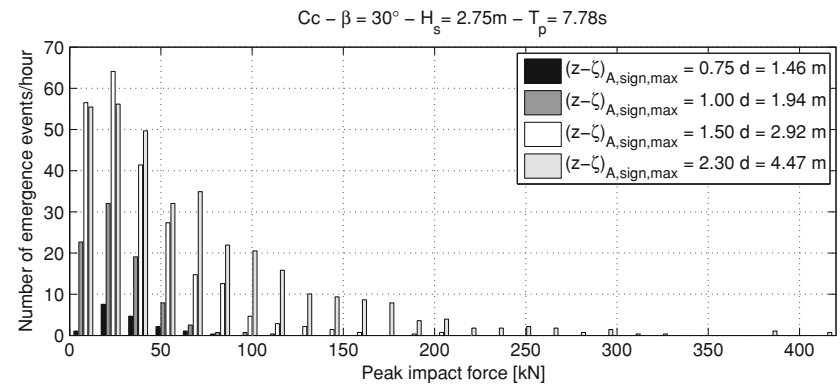

Fig. 16 Number of emergence events per hour as a function of the peak impact force for the $30^{\circ}$ cone, sea state: $H_{\mathrm{s}}=2.75 \mathrm{~m}$, $T_{\mathrm{p}}=7.78 \mathrm{~s}$

bars of Figs. 15 and 16 can be compared with the dark grey bars of Figs. 11, 12, 13 and 14, as the restrictions on the relative significant amplitude are 2.92 and $3.00 \mathrm{~m}$, respectively. There is a huge difference between the response of the $30^{\circ}$ cone and the two other shapes, both concerning the number of emergences and the impact velocity. For the least stringent constraint on the $30^{\circ}$ cone, i.e. $(z-\zeta)_{A, \text { sign }} \leq 2.30 d$, the number of emergence events per hour has risen to a considerable value of 342 , which is equivalent to an emergence occurrence probability of $63.0 \%$. Such situations should be avoided by tuning the buoy away from resonance, i.e. by decreasing the supplementary mass and increasing the external damping. For comparison, the buoy rises out of the water only 17 times per hour with the most stringent constraint $(\alpha=0.75)$, corresponding to an occurrence probability of $3.1 \%$. With the intermediate constraint $(\alpha=1.00)$, the buoy loses contact with the water surface approximately 86 times per hour, corresponding to an occurrence probability of almost $15.8 \%$. In both cases the impact velocities are relatively small compared to the weaker constraints, as illustrated in Fig. 13. For $\alpha=1.50$, the buoy releases the water about 230 times per hour, which gives a high occurrence probability of $42.2 \%$. Assuming that the buoy responses are Rayleigh distributed, the occurrence probabilities would be $2.9,13.5$ and $41.1 \%$, respectively, which are close to the calculated figures. 
These numbers show that the implementation of slamming constraints can significantly reduce the slamming occurrence probability. For a constraint with $\alpha=0.75$ compared to $\alpha=1.50$, the number of emergences is reduced by a factor of 14 , whereas the power absorbed by the $30^{\circ}$ cone is only decreased by 43 and $48 \%$ for the intermediate and energetic sea states, respectively. Applying the same constraints to the hemisphere and the $45^{\circ}$ cone, the power absorption is reduced by only 30 and $43 \%$ for the same respective sea states.

It has been shown that a buoy which is controlled according to very weak constraints (e.g. $\alpha=2.3$ ) is subjected to excessive slamming. Apart from slamming, there are other reasons why these control situations should be avoided, such as the large buoy motions that are associated with this case. In fact, for practical reasons, many devices have limitations on the maximum stroke of the buoy. For $\alpha=2.3$, the significant amplitude of the buoy motion is $4.9 \mathrm{~m}$, which is very large, especially compared to the incident wave height $\left(H_{\mathrm{s}}=2.75 \mathrm{~m}\right)$. Another problem is the very large tuning forces that are required to obtain this tuning. The significant amplitude of the tuning force required is $775 \mathrm{kN}$ compared to $117 \mathrm{kN}$ for the damping force to enable power extraction. Depending on how this tuning force needs to be realised, e.g. by the generator, this could lead to a very costly solution.

It should be reiterated at this point that the reliability of the model can be questioned for the case where the buoy operates very close to resonance. Nevertheless, the conclusion remains that such a situation is unrealistic and will never be aimed for. Also, the restriction where $\alpha$ equals 1.50, which gives rise to an unwanted high emergence occurrence probability of above $40 \%$, must be avoided in practice. Within this context it is concluded that the theoretical power absorption values for $\alpha=1.5-$ $\infty$, as mentioned in Table 1, are not practically achievable, except for the smaller sea states where slamming seldom occurs. The most realistic constraints are the stricter constraints with $\alpha$ values that are smaller than or equal to 1. Moreover, smaller control forces and buoy strokes need to be involved. For an $\alpha$ value of 1 and sea state $2\left(H_{\mathrm{s}}=2.75 \mathrm{~m}, T_{\mathrm{p}}=7.783 \mathrm{~s}\right)$, the significant amplitude of the buoy motion is $3.3 \mathrm{~m}$ and the significant amplitudes of the tuning and damping forces are 515 and $142 \mathrm{kN}$, respectively. If the $\alpha$ value equals 0.75 , the significant motion amplitude is $2.47 \mathrm{~m}$ and the significant amplitudes of the tuning and damping forces are equal to 354 and $154 \mathrm{kN}$, respectively. In order to reduce the power absorption penalty from the slamming constraints, it is advisable to increase the draft of the buoy, particularly if the considered structure hardly allows any slamming at all.

\section{Conclusion}

Point absorbers are generally tuned towards the incident wave frequencies to increase the power absorption. However, this may cause heavy slamming, and for this reason the theoretically optimum control values often represent unrealistic solutions. Slamming effects have been investigated for three sea states and three buoy shapes: two cones with deadrise angles of $45^{\circ}$ and $30^{\circ}$, and a hemisphere with a waterline diameter of $5 \mathrm{~m}$. For a tuned buoy, the probability of emergence increases dramatically with increasing wave height. In very small waves the buoys may absorb the theoretical maximum power, while slamming phenomena rarely occur. In more energetic waves the floater motions become larger and the buoys rise out of the water very frequently if they are tuned towards the dominant incident wave frequencies. The risk of slamming can be reduced by adjusting the control parameters of the buoy, i.e. the tuning and damping forces. Three different levels of slamming restrictions were introduced, which diminished the emergence occurrence probability to approximately 42,16 and $3 \%$. Going from the mildest to the most stringent constraint, the risk of emergence is reduced by a factor of almost 14 , while the power absorption for the hemisphere and the $45^{\circ}$ cone is only reduced by $30-43 \%$ for the intermediate and energetic sea states, respectively. The probability of emergence is greatly affected by the buoy draft. The same constraints reduce the power more severely for the $30^{\circ}$ cone, which has a draft of less than $2 \mathrm{~m}$. Slamming constraints not only limit the number of emergences; they also have the benefit of reducing the buoy strokes and control forces required.

High peak loads can be associated with slamming. Depending on the slamming constraints, the order of magnitude of the impact forces ranges from small values up to more than $300 \mathrm{kN}$ for the buoys with diameters of $5 \mathrm{~m}$ considered here. These forces may ultimately lead to fatigue problems for the structures if no measures are taken. The magnitude of these forces is significantly influenced by the buoy shape. According to the formulae of Shiffman and Spencer [37] and Miloh [27], the difference in peak loads between the $45^{\circ}$ cone and the hemisphere is a factor of 2 , whereas the difference in power absorption is only $4-8 \%$. A ratio of approximately 1.5 is found between the peak loads of the $30^{\circ}$ and $45^{\circ}$ cones. This illustrates the importance of considering slamming phenomena during the shape design process, aside from power absorption considerations.

To avoid problems with slamming, attention should be paid to the buoy geometry: drafts that are too small should be avoided, as should (local) deadrise angles that are too small, since small deadrise angles imply large impact pressures and forces. Secondly, optimal control strategies should not focus solely on power absorption; they should also consider emergence risks. Implementing slamming 
constraints in the control strategy might be essential in order to reduce slamming. Since these constraints are associated with power losses, the tolerable level of slamming is an economic balance between power absorption profits and material costs.

Acknowledgments This research was funded by a Ph.D. grant from the Institute of Promotion of Innovation Through Science and Technology in Flanders (IWT-Vlaanderen), Belgium.

\section{References}

1. Peseux B, Gornet L, Donguy B (2005) Hydrodynamic impact: numerical and experimental investigations. J Fluids Struct 21(3):277-303

2. Wienke J, Oumeraci H (2005) Breaking wave impact force on a vertical and inclined slender pile-theoretical and large-scale model investigations. Coast Eng 52(5):435-462

3. Bjerrum A (2008) The Wave Star Energy concept. In: 2nd International Conference on Ocean Energy, Brest, France, 15-17 Oct 2008

4. Goda Y (2008) Random seas and design of maritime structures. World Scientific, Singapore

5. WAMIT, Inc. (2006) WAMIT user manual. WAMIT, Inc., Chestnut Hill (see http://www.wamit.com/manual.htm)

6. Vantorre M, Banasiak R, Verhoeven R (2004) Modelling of hydraulic performance and wave energy extraction by a point absorber in heave. Appl Ocean Res 26:61-72

7. Budal K, Falnes J, Iversen LC, Hals T, Onshus T (1981) Model experiment with a phase-controlled point absorber. In: 2nd International Symposium on Wave and Tidal Energy, Cambridge, UK, 23-25 September 1981, pp 191-206

8. Babarit A, Duclos G, Clément AH (2004) Comparison of latching control strategies for a heaving wave energy device in random sea. Appl Ocean Res 26(5):227-238

9. De Backer G, Vantorre M, Banasiak R, Beels C, De Rouck J (2007) Numerical modelling of wave energy absorption by a floating point absorber system. In: 17th International Offshore and Polar Engineering Conference, Lisbon, Portugal, 1-6 July 2007

10. De Backer G, Vantorre M, Banasiak R, De Rouck J, Beels C, Verhaeghe H (2007) Performance of a point absorber heaving with respect to a floating platform. In: 7th Eur Wave and Tidal Energy Conference, Porto, Portugal, 11-14 Sept 2007

11. von Karman $T$ (1929) The impact of seaplane floats during landing (Tech Rep 321). National Advisory Committee for Aeronautics, Washington

12. Wagner H (1932) Über stoss- und gleitvorgänge an der oberfläche von flüssigkeiten. Z Angew Math Mech 12:193-215

13. Malleron N, Scolan Y-M, Korobkin AA (2007) Some aspects of a generalized Wagner model. In: 22nd IWWWFB, Plitvice, Croatia, 15-18 April 2007, pp 137-140

14. Chuang SL (1969) Theoretical investigations on slamming of cone-shaped bodies. J Ship Res 13:276-283

15. Toyama Y (1996) Flat plate approximation in the three-dimensional slamming (in Japanese). J Soc Naval Architects Jpn 179:271-279

16. Faltinsen OM, Zhao R (1997) Water entry of ship sections and axisymmetric bodies (Tech Rep 818). In: AGARD FDP and Ukraine Institute of Hydromechanics Workshop on High Speed Body Motion in Water, Kiev, Ukraine, 1-3 Sept 1997

17. Scolan Y-M, Korobkin AA (2001) Three-dimensional theory of water impact. Part 1. Inverse Wagner problem. J Fluid Mech 440:293-326
18. Oger G, Doring M, Leroyer A, Alessandrini B, Visonneau M (2004) SPH and finite volume simulations of a wedge water entry. In: 14th International Offshore and Polar Eng Conference, vol 4, Toulon, France, 23-28 May 2004, pp 554-560

19. Constantinescu A, Bertram V, Fuiorea I, Neme A (2005) Wedgeshaped shell structure impacting a water surface. In: ASME Pressure Vessels and Piping Conference, vol 4, Denver, CO, $17-21$ July 2005 , pp 55-62

20. Kleefsman KMT, Fekken G, Veldman AEP, Iwanowski B, Buchner B (2005) A volume-of-fluid based simulation method for wave impact problems. J Comput Phys 206(1):363-393

21. Leroyer A, Hay A, Visonneau M (2007) Flow/motion interaction using a Navier-Stokes solver with automatic local grid refinement; application to slamming (in French). Mecanique Industries $8: 151-160$

22. Vandamme J, Zou Q, Reeve D, Zhang Y (2009) Modelling the movement and wave impact of a floating object using SPH. In: 8th Eur Wave and Tidal Energy Conference, Uppsala, Sweden, 7-10 Sept 2009, pp 646-653

23. De Backer G, Vantorre M, Victor S, De Rouck J, Beels C (2008) Investigation of vertical slamming on point absorbers. In: 27th International Conference on Offshore Mechanics and Arctic Engineering, Estoril, Portugal, 15-20 June 2008

24. De Backer G, Vantorre M, Beels C, De Pré J, Victor S, De Rouck J, Blommaert C, Van Paepegem W (2009) Experimental investigation of water impact on axisymmetric bodies. Appl Ocean Res 31:143-156

25. Shiffman M, Spencer DC (1951) The force of impact on a cone striking a water surface. Comm Pure Appl Math 4:379-417

26. Battistin D, Iafrati A (2003) Hydrodynamic loads during water entry of two-dimensional and axisymmetric bodies. J Fluids Struct 17(5):643-664

27. Miloh T (1991) On the initial-stage slamming of a rigid sphere in a vertical water entry. Appl Ocean Res 13(1):34-48

28. Zhao R, Faltinsen OM, Aarsnes J (1996) Water entry of arbitrary two-dimensional sections with and without flow separation. In: Proceedings of 21st Symposium on Naval Hydrodynamics, Trondheim, Norway, 24-28 June 1996, pp 408-423

29. Zhao R, Faltinsen OM (1998) Water entry of arbitrary axisymmetric bodies with and without flow separation. In: Proceedings of 22nd Symposium on Naval Hydrodynamics, Washington, DC, 9-14 Aug 1998

30. Faltinsen OM, Chezhian M (2005) A generalized Wagner method for three-dimensional slamming. J Ship Res 24(4):279-287

31. Moghisi M, Squire PT (1981) An experimental investigation of the initial force of impact on a sphere striking a liquid surface. J Fluid Mech 108:133-146

32. Faltinsen OM (2000) Hydroelastic slamming. J Mar Sci Technol 5:49-65

33. Scolan Y-M (2004) Hydroelastic behaviour of a conical shell impacting on a quiescent-free surface of an incompressible liquid. J Sound Vib 277:163-203

34. Cummins WE (1962) The impulse response function and ship motions. Schiffstechnik (9):101-109

35. Duclos G, Clément AH, Chatry G (2001) Absorption of outgoing waves in a numerical wave tank using a self-adaptive boundary condition. Int J Offshore Polar Eng 11(3):168-175

36. De Backer G, Vantorre M, De Beule K, Beels C, De Rouck J (2009) Experimental investigation of the validity of linear theory to assess the behaviour of a heaving point absorber at the Belgian continental shelf. In: 28th International Conference on Ocean, Offshore and Arctic Engineering, Honolulu, HI, 31 May-5 June 2009

37. Shiffman M, Spencer DC (1945) The force of impact on a sphere striking a water surface (Applied Math Panel, National Defense Research Committee, Rep No. 105). Applied Mathematics Group, New York University, New York 